\title{
Predictive factors of medullary infarction after endovascular internal trapping using coils for vertebral artery dissecting aneurysms
}

\author{
Masanori Aihara, MD, PhD, ${ }^{1}$ Isao Naito, MD, ${ }^{2}$ Tatsuya Shimizu, MD, PhD, \\ Masahiro Matsumoto, MD, PhD, ${ }^{3}$ Ken Asakura, MD, ${ }^{4}$ Naoko Miyamoto, MD, PhD, ${ }^{2}$ and \\ Yuhei Yoshimoto, MD, PhD1 \\ 1Department of Neurosurgery, Gunma University Graduate School of Medicine; ${ }^{2}$ Department of Neurosurgery, Geriatrics \\ Research Institute and Hospital; " ${ }^{4}$ Department of Neurosurgery, Maebashi Red Cross Hospital, Maebashi; and ${ }^{3}$ Department of \\ Neurosurgery, Tatebayashi Kosei Hospital, Tatebayashi, Gunma, Japan
}

OBJECTIVE The first choice of treatment in cases of vertebral artery dissecting aneurysms (VADAs) is endovascular internal trapping (EIT) of the dissecting segment using coils. However, this procedure carries the risk of medullary infarction, and the risk factors for this complication are not well understood. This study investigated the risk factors causing medullary infarction.

METHODS One hundred patients who underwent EIT for VADAs were included in this study. Ninety-three patients presented with subarachnoid hemorrhage. In cases involving the posterior inferior cerebellar artery (PICA), partial internal trapping targeting the ruptured site was performed to preserve the PICA. The VADAs were classified into the distal VA stump group, proximal VA stump group, and entire VA stump group, according to the location of VA segments without adequate flow-out vessels (such as the PICA [VA stump]) at risk of delayed thrombosis. The occurrence of medullary infarction was examined in each group using diffusion-weighted MRI and/or clinical symptoms. Various measurements were performed on digital subtraction angiography, and the risk factors for medullary infarction were analyzed.

RESULTS Medullary infarction occurred in 30 patients, affecting the posterolateral medulla in 27 patients and the anteromedial medulla in 3 patients. Medullary infarction occurred in 3 of 47 patients (6\%) in the distal VA stump group, 10 of 19 patients (53\%) in the proximal VA stump group, and 17 of 34 patients (50\%) in the entire VA stump group. The length of trapping was significantly longer in the infarction group than in the noninfarction group but did not differ among the 3 groups. Total length (length of trapping plus VA stump) was a risk factor for medullary infarction in the proximal VA stumps. CONCLUSIONS The primary risk factor for medullary infarction after EIT is not the length of trapping; rather, it is the anatomical location of the VADAs. The risk of medullary infarction is low in cases with distal VA stumps, but the symptoms are severe. Preservation of the origin of the anterior spinal artery can reduce the risk of medullary infarction. The risk of medullary infarction is high in cases with proximal VA stumps, but the symptoms are mild. A shorter length of trapping, although less likely to lead to complications, cannot prevent medullary infarction because the total length depends on the anatomical location of the PICA and not on the surgical technique. Reconstructive therapy should be indicated for patients with ruptured VADAs at high risk of severe ischemic complications (e.g., patients with hypoplasia of the contralateral VA or cases involving the PICA or anterior spinal artery, which are inappropriate for partial internal trapping) or for patients with unruptured VADAs.

https://thejns.org/doi/abs/10.3171/2017.2.JNS162916

KEY WORDS endovascular internal trapping; medullary infarction; predictive factor; vertebral artery dissecting aneurysm; vascular disorders; interventional neurosurgery

ABBREVIATIONS AICA = anterior inferior cerebellar artery; ASA = anterior spinal artery; EIT = endovascular internal trapping; PICA = posterior inferior cerebellar artery; $\mathrm{SAH}=$ subarachnoid hemorrhage; VADA = vertebral artery dissecting aneurysm.

SUBMITTED November 22, 2016. ACCEPTED February 2, 2017.

INCLUDE WHEN CITING Published online August 11, 2017; DOI: 10.3171/2017.2.JNS162916. 
$\mathrm{R}$ UPTURED vertebral artery dissecting aneurysms (VADAs) show high rates of rebleeding, most frequently within 24 hours, and the prognosis is poor. ${ }^{17,21,26,28,30}$ Therefore, early prevention of rebleeding using direct surgical or endovascular procedures is essential. Endovascular internal trapping (EIT) of the dissecting segment using coils is the first choice of treatment for VADAs, especially in ruptured cases, because EIT is the most reliable option to prevent rebleeding. ${ }^{6,8,10,24,25}$ However, this procedure carries the risk of medullary infarction, and occurrence of this complication is unpredictable. , $, 8,9,17^{-17}$ This study retrospectively reviewed 100 consecutive patients with VADAs who underwent EIT and investigated the risk factors causing medullary infarction.

\section{Methods}

\section{Patient Demographic Data and Clinical Characteristics}

One hundred forty-four patients with VADAs underwent endovascular treatment between 1993 and 2015 in our hospital or affiliated hospitals. One hundred twentytwo patients were treated with EIT, and 22 patients were treated with stent-assisted coiling because of hypoplasia or aplasia of the contralateral VA or involvement of the anterior spinal artery (ASA) or posterior inferior cerebellar artery (PICA) in the dissecting segment. Twenty-two patients (8 patients with medullary infarction before treatment, 1 patient treated with occipital artery-PICA bypass followed by EIT, and 13 patients lost from follow-up) were excluded. Finally, 100 patients (75 men and 25 women, age 29-86 years [mean 50 years]) were included in this study.

The VADAs were classified into 5 types according to the positional relationship of the aneurysms to the PICA: proximal to PICA, distal to PICA, PICA involved, com- mon trunk of anterior inferior cerebellar artery (AICA)PICA, and extracranial origin of PICA. After EIT, the VADAs were divided into the proximal VA stump group, distal VA stump group, and entire VA stump group, according to the location of VA segments without adequate flow-out vessels (such as the PICA [VA stump]) at risk of delayed thrombosis (Fig. 1). Patients' medical charts and the findings of CT, MRI, and cerebral angiography were evaluated. Medullary infarction was diagnosed based on diffusion-weighted MRI findings and/or clinical symptoms.

This study was approved by the institutional review board of Gunma University Graduate School of Medicine and performed in accordance with the ethical standards laid out in the 1964 Declaration of Helsinki and its later amendments. The opt-out was posted on our homepage prior to inclusion in this study instead of obtaining informed consent from all study subjects.

\section{Endovascular Procedures}

EIT was performed during the acute stage in cases of ruptured aneurysms. Conservative observation consisting of bed rest and blood pressure control was initially performed. Intervention was indicated if enlargement of the aneurysmal dilation was detected by follow-up examinations in cases of unruptured aneurysms. EIT was performed while patients were under general anesthesia. A 6-F or 7-F balloon or plain guiding catheter was inserted in the affected VA, and a microcatheter was introduced into the aneurysmal dilation. Then, the detachable coils were inserted from the aneurysmal dilation to the proximal parent artery until complete obliteration was obtained. Proximal flow control was achieved by inflating the balloon of the guiding catheter if necessary. Partial internal

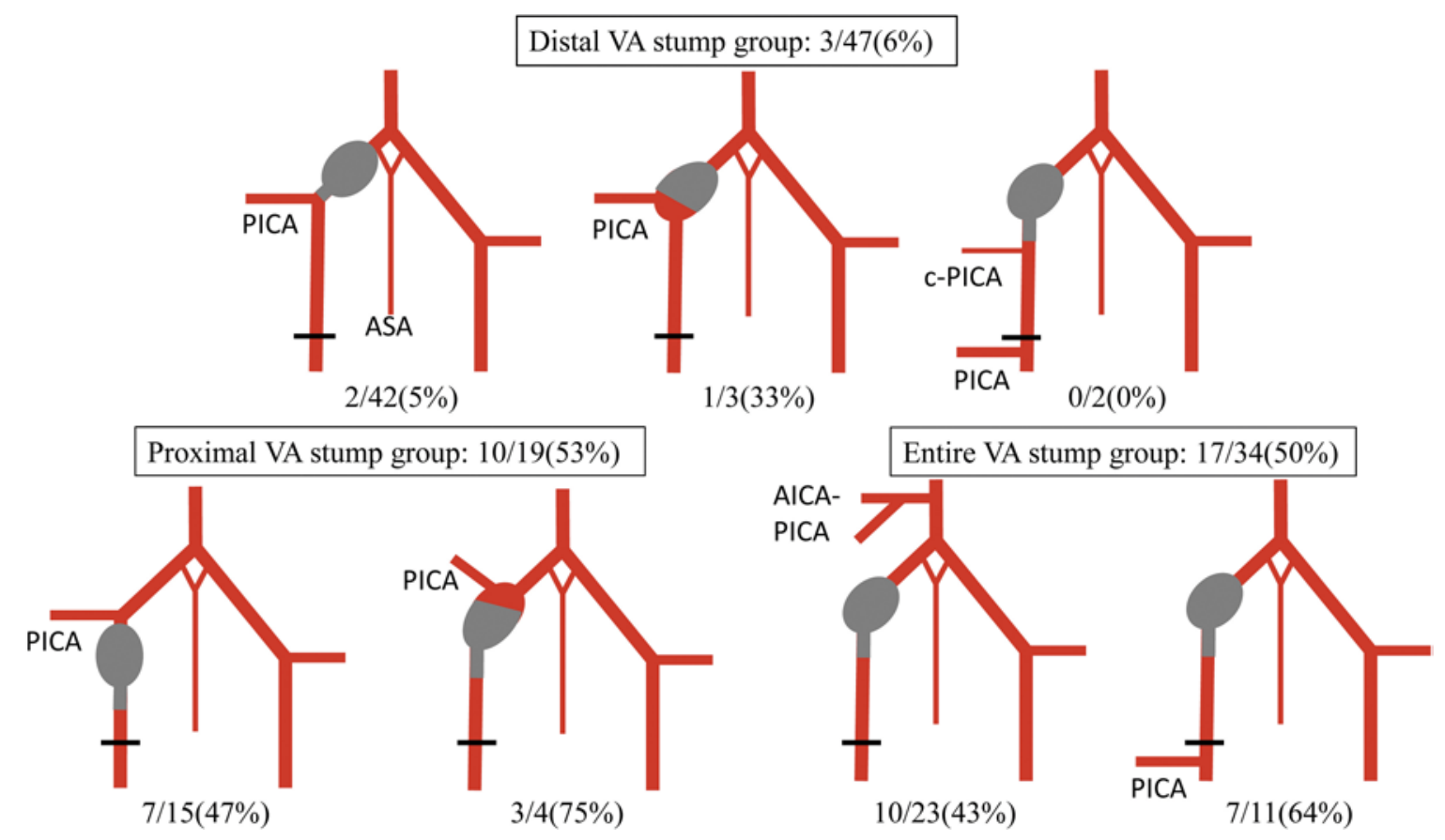

FIG. 1. Classification of VADAs into 3 groups and incidence of medullary infarction. c-PICA = complementary PICA. 
trapping targeted to the ruptured site in cases of the PICA-involved type (that is, proximal or distal to the PICA) was performed to preserve the PICA. Aspirin $200 \mathrm{mg}$ was administered prior to the procedure in most patients. Heparin $100 \mathrm{U} / \mathrm{kg}$ was administered at the beginning of the procedure, and $1000 \mathrm{U}$ was added every 1 hour. The administration of antiplatelet agents was continued for approximately 2 weeks or longer after the procedure, and additional heparin was not infused.

\section{Radiological Measurements}

The length of the aneurysm and the diameter of the affected VA were measured on preoperative angiography. The length of trapping by the coils and the length of the VA stump were measured on postoperative angiography. The length of the VA stump was defined as the distance from the level of the foramen magnum to the proximal end of the coils in the proximal VA stump group, the distance from the VA union to the distal end of the coils in the distal VA stump group, and both distances in the entire VA stump group. Total length was defined as the length of trapping plus the length of the stump. The measurements were performed using a workstation or with reference to the diameter of the guiding catheter in cases treated during the early period.

\section{Statistical Analysis}

The relationships between medullary infarction and various factors were initially examined by univariate analysis using the $\chi^{2}$ test and Fisher's exact test to identify the potential risk factors. Predictive factors for medullary infarction were analyzed similarly. A $p$ value $<0.05$ was considered to be statistically significant. All analyses were performed using commercial software (SPSS Statistics version 22; IBM).

\section{Results}

\section{Clinical Characteristics and Location of the VADAs}

Ninety-three patients (93\%) presented with subarachnoid hemorrhage (SAH) and 7 patients (7\%) without SAH (Table 1). The preoperative Hunt and Kosnik grades were I-III in 57 patients (57\%), and IV and V in 36 patients $(36 \%){ }^{7}$ All VADAs were unilateral and were located on the right VA in 65 patients (65\%). VADAs were distal to PICA type in 42 patients (42\%), proximal to PICA type in $15(15 \%)$, PICA-involved type in 7 (7\%), common trunk of AICA-PICA type in 23 (23\%), and extracranial origin of PICA type in 13 (13\%).

\section{Endovascular Treatment}

EIT was successfully performed and the parent arteries were completely occluded in all patients based on the final bilateral vertebral artery angiography studies. In 7 patients with the PICA-involved type, the proximal portion of the PICA was embolized in 4 and the distal portion of the PICA in 3. The PICAs were preserved in all patients, but 1 patient developed cerebellar infarction due to delayed occlusion of the PICA, and internal and external decompressions were required. The visualized ASAs were preserved
TABLE 1. Demographic data and clinical characteristics of the patients

\begin{tabular}{lc}
\hline \multicolumn{1}{c}{ Variable } & Value (\%) \\
\hline No. of cases & 100 \\
\hline Mean age in yrs \pm SD & $50 \pm 10$ \\
\hline Sex, male & $75(75)$ \\
\hline Hunt \& Kosnik grade & $7(7)$ \\
\hline 0 & $57(57)$ \\
\hline I-III & $36(36)$ \\
\hline IV \& V & $65(65)$ \\
\hline VADA (rt) & \\
\hline Location of VADA & $42(42)$ \\
\hline Distal to PICA & $15(15)$ \\
\hline Proximal to PICA & $7(7)$ \\
\hline PICA involved & $23(23)$ \\
\hline Common trunk of AICA-PICA & $13(13)$ \\
\hline Extracranial origin of PICA &
\end{tabular}

in all patients except for 1 patient, in whom the ASA was involved in the dissecting segment, and were opacified by the final contralateral VA injection. Recanalization was observed in 1 patient, requiring additional endovascular treatment. No patients developed rebleeding.

\section{Incidence of Medullary Infarction}

Medullary infarction was observed in 30 patients, including posterolateral infarction in $27(90 \%)$ and anteromedial infarction in 3 patients $(10 \%$, distal to PICA type in 2 and PICA-involved type embolized in the distal portion to the PICA in 1) (Table 2). The age, sex, and presence or absence of SAH had no significant correlations with the occurrence of medullary infarction. Medullary infarction occurred in 2 of 42 patients with the distal to PICA type (5\%), 7 of 15 patients with the proximal to PICA type (47\%), 4 of 7 patients with the PICA-involved type (57\%), 10 of 23 patients with the common trunk of AICA-PICA type (43\%), and 7 of 13 patients with the extracranial origin of PICA type (54\%). In the 7 patients with the PICA-involved type, medullary infarction developed in 3 of 4 patients treated with embolization of the proximal portion to the PICA, and in 1 of 3 patients treated with embolization of the distal portion to the PICA. The incidence of medullary infarction was significantly lower in the distal to PICA type $(\mathrm{p}<0.001)$ than in the other types.

After EIT, 3 of the 7 patients with the PICA-involved type were classified into the distal VA stump group and 4 into the proximal VA stump group. Two of the 13 patients with extracranial origin of PICA type were classified into the distal VA stump group because the complementary PICA arose from just proximal to the aneurysm. The incidence of medullary infarction was 53\% (10 of 19) in the proximal VA stump group, 6\% (3 of 47) in the distal VA stump group, and $50 \%$ (17 of 34) in the entire VA stump group, which was significantly lower in the distal VA stump group ( $\mathrm{p}<0.001 ;$ Fig. 1). 
TABLE 2. Incidence of medullary infarction

\begin{tabular}{|c|c|c|c|c|}
\hline Variable & Total & Infarction Group (\%) & Noninfarction Group (\%) & p Value \\
\hline No. of cases & 100 & 30 & 70 & \\
\hline Mean age in yrs $\pm S D$ & & $52 \pm 8$ & $49 \pm 11$ & $0.055^{*}$ \\
\hline Sex & & & & $0.450 \dagger$ \\
\hline Male & 75 & $24(32)$ & $51(68)$ & \\
\hline Female & 25 & $6(24)$ & $19(76)$ & \\
\hline SAH & & & & $0.649 \dagger$ \\
\hline Positive & 93 & $28(30)$ & $65(70)$ & \\
\hline Negative & 7 & $2(29)$ & $5(71)$ & \\
\hline Location of VADA & & & & $<0.001 \dagger$ \\
\hline Distal to PICA & 42 & $2(5)$ & $40(95)$ & \\
\hline Proximal to PICA & 15 & $7(47)$ & $8(53)$ & \\
\hline PICA involved & 7 & $4(57)$ & $3(43)$ & \\
\hline Common trunk of AICA-PICA & 23 & $10(43)$ & $13(57)$ & \\
\hline Extracranial origin of PICA & 13 & $7(54)$ & $6(46)$ & \\
\hline
\end{tabular}

\section{Radiological Measurements and Medullary Infarction}

Measurements were possible in 74 patients, including 14 patients in the proximal VA stump group, 34 in the distal VA stump group, and 26 in the entire VA stump group (27 patients in the infarction group and 47 in the noninfarction group). The length of the aneurysm did not differ among the 3 groups, but the length of trapping was shorter in the distal VA stump group than in the entire VA stump group ( $<<0.001$; Table 3 ). The length of the aneurysm had no significant relationship with the development of medullary infarction. The length of trapping was significantly longer in the infarction group than in the noninfarction group $(\mathrm{p}=0.032$ ), but did not differ among the 3 groups (Table 4).

After EIT, 40 proximal VA stumps (14 patients in the proximal VA stump group and 26 in the entire VA stump group) and 60 distal VA stumps (34 patients in the distal VA stump group and 26 in the entire VA stump group) were formed. Among the proximal VA stumps, total length was significantly longer $(p=0.041)$ in the infarction group than in the noninfarction group, but the length of trapping and length of stump did not differ between the infarction and noninfarction groups. Among the distal VA stumps, the length of trapping, length of stump, and total length did not differ between the infarction and noninfarction groups (Table 5).

\section{Medullary Infarction and Outcome}

Glasgow Outcome Scale scores of 93 patients with SAH who were evaluated at hospital discharge showed good recovery in 50 patients $(54 \%)$, moderate disability in $23(25 \%)$, severe disability in $12(13 \%)$, and death in 8 (9\%) (Table 6). Of 7 patients without SAH, good recovery was observed in 6 patients $(86 \%)$ and moderate disability in $1(14 \%)$. Medullary infarction was a significant risk factor for unfavorable outcome (severe disability, persistent vegetative state, and death), according to the Glasgow Out- come Scale in patients with Hunt and Kosnik Grades I-III and in all patients $(\mathrm{p}<0.001)$.

\section{Discussion}

EIT of the dissecting segment using coils is the most commonly used treatment option for VADAs. ${ }^{68}$ However, this procedure carries the risk of medullary infarction, and the risk factors for this complication are not well understood. ${ }^{6,8,9,17}$ Reported occurrence rates of medullary infarction are $47 \%$ and $38 \%, 4,9$ similar to our finding of $30 \%$. Medullary infarction results from occlusion of the perforators arising from the VA or the PICA caused by the dissection itself, occlusion of the dissecting segment by coils, and delayed thrombosis of the VA stump. In the distal to PICA type, the perforators involved in the VA stump considerably differed according to the location of the PICA; therefore, we divided the distal to PICA type into intracranial origin and extracranial origin of the PICA. The distal to PICA type with intracranial origin of the PICA had lower risk of medullary infarction than other types of VADAs $(p<0.001)$. Furthermore, the VADAs were divided into 3 groups: proximal VA stump, distal VA stump, and entire VA stump groups (Fig. 1). The occurrence rate of medullary infarction was higher in the proximal VA stump and entire VA stump groups than in the distal VA stump group ( $p<0.001)$, and $90 \%$ of cases of medullary

TABLE 3. Length of aneurysm and length of trapping

\begin{tabular}{ccc}
\hline \multicolumn{1}{c}{ Group } & $\begin{array}{c}\text { Length of } \\
\text { Aneurysm }\end{array}$ & $\begin{array}{c}\text { Length of } \\
\text { Trapping }\end{array}$ \\
\hline Proximal VA stump $(\mathrm{n}=14)$ & $10.8 \pm 2.9$ & $15.5 \pm 5.0$ \\
\hline Distal VA stump $(\mathrm{n}=34)$ & $10.7 \pm 4.4$ & $12.2 \pm 4.2$ \\
\hline Entire VA stump $(\mathrm{n}=26)$ & $10.9 \pm 4.3$ & $17.8 \pm 9.0$ \\
\hline
\end{tabular}

Values are presented as the mean $\pm \mathrm{SD}$ in $\mathrm{mm}$. 
TABLE 4. Length of trapping and medullary infarction

\begin{tabular}{lccc}
\hline \multicolumn{1}{c}{ Group } & Infarction Group $(n=27)$ & Noninfarction Group $(n=47)$ & $p$ Value \\
\hline Proximal VA stump $(n=14)$ & $15.7 \pm 5.5(n=10)$ & $14.9 \pm 4.1(n=4)$ & 1.000 \\
\hline Distal VA stump $(n=34)$ & $12.5 \pm 1.6(n=3)$ & $12.1 \pm 4.4(n=31)$ & 1.000 \\
\hline Entire VA stump $(n=26)$ & $20.3 \pm 10.7(n=14)$ & $15.1 \pm 5.8(n=12)$ & 0.200 \\
\hline All 3 groups & $17.7 \pm 8.7$ & $13.1 \pm 4.9$ & 0.032 \\
\hline
\end{tabular}

Values are presented as the mean $\pm \mathrm{SD}$ in $\mathrm{mm}$.

* Mann-Whitney U-test.

infarction occurred in the posterolateral medulla supplied by perforators coming from the proximal VA. Other reports have also shown that lateral medullary syndrome is more likely to occur than medial medullary syndrome., ${ }^{4,9}$

The perforators arising from the proximal VA supply the posterolateral medulla, and occlusion of these vessels results in lateral medullary syndrome (the so-called Wallenberg syndrome). ${ }^{12,13,15,20}$ The perforators arising from the proximal VA and the PICA are complementary. If the PICA is not absent in the intracranial segment of the VA (e.g., the common trunk of the AICA-PICA or extracranial origin of the PICA type), the perforators to the posterolateral medulla originate from the VA. ${ }^{5,20}$ In such cases, occlusion of the VA is more likely to cause lateral medullary infarction, although the incidence of medullary infarction in the proximal to PICA type with intracranial origin of the PICA was almost equal to the incidence in the types of common trunk of AICA-PICA or extracranial origin of PICA in our series.

In contrast, perforators arising from the distal VA containing the ASA enter the foramen cecum or anterior median sulcus and supply the anteromedial medulla. ${ }^{18,19}$ Therefore, occlusion of these vessels results in medial medullary syndrome with severe neurological symptoms, such as hemiparesis or respiratory disorders. ${ }^{12,14}$ Perforators arising from the distal VA have rich anastomoses with perforators from the contralateral VA, the lower basilar artery, the ASA, and the PICA. ${ }^{18,20}$ Moreover, the presence of ASA as a flow-out vessel prevents delayed thrombosis of the VA stump: ${ }^{11,29}$ as a result, medullary infarction is less likely to occur. Indeed, the distal VA stumps were opacified by retrograde flow from the VA union in most patients, whereas the proximal VA stumps were not opacified from the level of the foramen magnum on immediate postoperative angiography in our series. In 3 patients with medial medullary syndrome, the ASA origins were preserved in 2 patients, but the ASA origin was subsequently embolized in 1 patient, in whom the ASA and the PICA were involved in the dissecting segment (Fig. 2). Preservation of ASA origin can reduce the risk of medial medullary infarction but cannot completely prevent delayed thrombosis or occlusion of perforators other than the ASA. Therefore, we propose that classifying the VADAs into our 3 groups based on the location of the VA segments without flowout vessels is useful for predicting the risk of medullary infarction.

The length of trapping is reported to be significantly longer in the infarction group than in the noninfarction group. ${ }^{4,9}$ In our series, the length of trapping was also a risk factor for medullary infarction, but no significant differences were found among the 3 groups. As shown in Table 3, the length of trapping was longer in the proximal VA stump and entire VA stump groups, resulting from antegrade flow or the absence of a flow-out vessel, than in the distal VA stump group, and the infarction group included many cases with proximal VA stump and entire VA stump whereas the noninfarction group included many cases with distal VA stump. Therefore, the primary risk factor for medullary infarction is not the length of trapping but the anatomical location of VADAs relative to the origin of the PICA. Total length was a risk factor for medullary infarction in cases with proximal VA stump. However, total length depends on the anatomical location of the PICA rather than the surgical technique. A shorter

TABLE 5. Radiological measurements and medullary infarction in cases with proximal VA stump and distal VA stump

\begin{tabular}{cccc}
\hline Variable & Infarction Group & Noninfarction Group & $p$ Value* \\
\hline Proximal VA stump $(\mathrm{n}=40) \dagger$ & $\mathrm{n}=24$ & $\mathrm{n}=16$ & 0.334 \\
\hline Length of trapping & $18.4 \pm 9.1$ & $15.0 \pm 9.1$ & 0.263 \\
\hline Length of stump & $20.2 \pm 9.6$ & $17.8 \pm 7.0$ & 0.041 \\
\hline Total length & $38.6 \pm 7.1$ & $32.8 \pm 7.4$ & 0.647 \\
\hline Distal VA stump $(\mathrm{n}=60) \ddagger$ & $\mathrm{n}=3$ & $14.8 \pm 7.4$ & 0.203 \\
\hline Length of trapping & $12.5 \pm 1.6$ & $11.4 \pm 4.3$ & 0.445 \\
\hline Length of stump & $17.1 \pm 8.0$ & $26.2 \pm 8.4$ & \\
\hline Total length & $29.5 \pm 7.6$ & & \\
\hline
\end{tabular}

Values are presented as the mean \pm SD in mm unless otherwise indicated.

* Mann-Whitney U-test.

† Fourteen patients in the proximal VA stump group and 26 patients in the entire VA stump group.

‡ Thirty-four patients in the distal VA stump group and 26 patients in the entire VA stump group. 
TABLE 6. Favorable outcome in the infarction and noninfarction groups

\begin{tabular}{cccc}
\hline $\begin{array}{c}\text { Hunt \& } \\
\text { Kosnik Grade }\end{array}$ & $\begin{array}{c}\text { Infarction } \\
\text { Group (\%) }\end{array}$ & $\begin{array}{c}\text { Noninfarction } \\
\text { Group (\%) }\end{array}$ & p Value* \\
\hline 0 & $2 / 2(100)$ & $5 / 5(100)$ & NA \\
\hline I-III & $8 / 15(53)$ & $41 / 42(98)$ & $<0.001$ \\
\hline IV \& V & $6 / 13(46)$ & $18 / 23(78)$ & 0.071 \\
\hline Total & $16 / 30(53)$ & $64 / 70(91)$ & $<0.001$ \\
\hline
\end{tabular}

NA = not applicable.

Favorable outcome was defined as good recovery and moderate disability according to the Glasgow Outcome Scale.

* Fisher's exact test.

length of trapping, although less likely to lead to complications, cannot prevent medullary infarction. The appropriate use of antiplatelet agents and anticoagulants can delay thrombosis of the VA stump, resulting in prevention of medullary infarction.

Reconstructive therapies such as stent-assisted coiling or stenting, which can preserve the patency of the parent artery, are available for the treatment of VADAs. ${ }^{1,23}$ Recently, the use of flow-diverter stents for a few cases of ruptured VADAs has been reported. ${ }^{2,3,22}$ However, these procedures carry higher risks of rebleeding and recanalization than EIT, 1,23,27 and antiplatelet therapy is necessary to prevent thromboembolic complications. ${ }^{2,3}$ Therefore, EIT is still the treatment of choice among the many treatment options for VADAs. Reconstructive therapy should be indicated for patients with ruptured VADAs at high risk of severe ischemic complications (e.g., hypoplasia of the contralateral VA or cases involving the PICA or ASA, which are inappropriate for target embolization) or for patients with unruptured VADAs. ${ }^{16}$

Some limitations to this study should be mentioned. First, diffusion-weighted images were obtained in most but not all patients, in particular patients treated during the early period or with severe neurological deficits caused by the SAH. Thus the number and location of medullary infarctions were incompletely assessed, and the size of medullary infarctions was not considered. Second, measurement of the length was not possible in all patients. In addition, it is not exact because the length changes with the exposure angle of the image, although the results will not be significantly different. Third, the outcome was assessed at hospital discharge in this study because follow-up was not possible in all patients. Long-term follow-up data are needed to evaluate the impact of medullary infarction on the outcome because some patients with medullary infarction recover well in the long term. Finally, although this is one of the largest studies in the field to our knowledge, the number of patients in some of our subgroups was small. Thus an analysis of a larger number of cases is needed to validate our results.

\section{Conclusions}

The primary risk factor for medullary infarction is not the length of trapping but the anatomical location of the VADAs. The risk of medullary infarction is low in cases
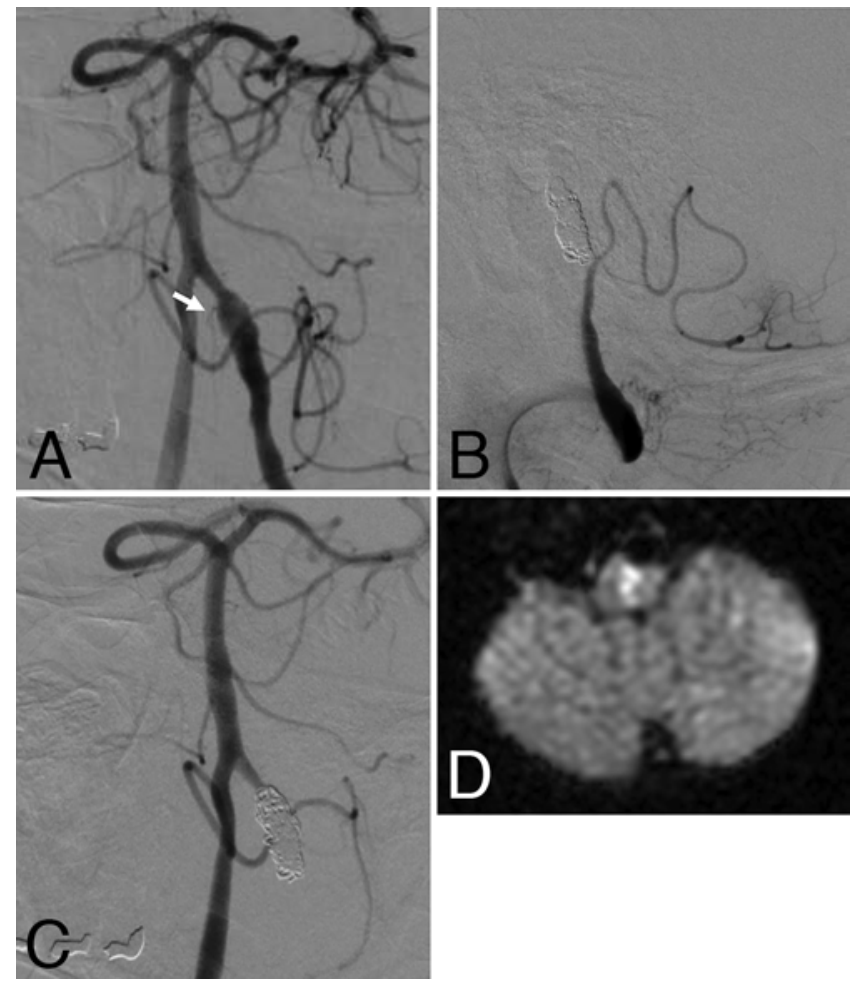

FIG. 2. Studies obtained in a 51-year-old man with a ruptured VADA manifesting as a severe disturbance of consciousness. A: Preoperative left VA angiogram showing involvement of the left PICA and ASA (arrow) in the dissecting segment. B: Left VA angiogram after EIT showing preservation of the PICA. C: Postoperative right VA angiogram showing occlusion of the ASA origin by the coils inserted in the aneurysm. D: Diffusion-weighted image obtained the next day, showing left paramedian medullary infarction.

with distal VA stumps, but the symptoms are severe. Preservation of the origin of the ASA can reduce the risk of medullary infarction. The risk of medullary infarction is high in cases with proximal VA stumps, but the symptoms are mild. A shorter length of trapping, although less likely to lead to complications, cannot prevent medullary infarction because the total length depends on the anatomical location of the PICA. Reconstructive therapy should be indicated for patients with ruptured VADAs at high risk of developing severe ischemic complications (e.g., hypoplasia of contralateral VA or cases involving the PICA or ASA, which are inappropriate for target embolization) or for patients with unruptured VADAs.

\section{References}

1. Ahn JY, Han IB, Kim TG, Yoon PH, Lee YJ, Lee BH, et al: Endovascular treatment of intracranial vertebral artery dissections with stent placement or stent-assisted coiling. AJNR Am J Neuroradiol 27:1514-1520, 2006

2. Chan RS, Mak CH, Wong AK, Chan KY, Leung KM: Use of the pipeline embolization device to treat recently ruptured dissecting cerebral aneurysms. Interv Neuroradiol 20:436441, 2014

3. Ducruet AF, Crowley RW, Albuquerque FC, McDougall CG: Reconstructive endovascular treatment of a ruptured vertebral artery dissecting aneurysm using the Pipeline embolization device. J Neurointerv Surg 5:e20, 2013 
4. Endo H, Matsumoto Y, Kondo R, Sato K, Fujimura M, Inoue $\mathrm{T}$, et al: Medullary infarction as a poor prognostic factor after internal coil trapping of a ruptured vertebral artery dissection. J Neurosurg 118:131-139, 2013

5. Fine AD, Cardoso A, Rhoton AL Jr: Microsurgical anatomy of the extracranial-extradural origin of the posterior inferior cerebellar artery. J Neurosurg 91:645-652, 1999

6. Hamada J, Kai Y, Morioka M, Yano S, Todaka T, Ushio Y: Multimodal treatment of ruptured dissecting aneurysms of the vertebral artery during the acute stage. J Neurosurg 99:960-966, 2003

7. Hunt WE, Kosnik EJ: Timing and perioperative care in intracranial aneurysm surgery. Clin Neurosurg 21:79-89, 1974

8. Iihara K, Sakai N, Murao K, Sakai H, Higashi T, Kogure S, et al: Dissecting aneurysms of the vertebral artery: a management strategy. J Neurosurg 97:259-267, 2002

9. Ikeda H, Imamura H, Mineharu Y, Tani S, Adachi H, Sakai $\mathrm{C}$, et al: Effect of coil packing proximal to the dilated segment on postoperative medullary infarction and prognosis following internal trapping for ruptured vertebral artery dissection. Interv Neuroradiol 22:67-75, 2016

10. Jin SC, Kwon DH, Choi CG, Ahn JS, Kwun BD: Endovascular strategies for vertebrobasilar dissecting aneurysms. AJNR Am J Neuroradiol 30:1518-1523, 2009

11. Kado K, Hirai S, Kobayashi S, Kobayashi E, Yamakami I, Uchino Y, et al: Potential role of the anterior spinal artery in preventing propagation of thrombus in a therapeutically occluded vertebral artery: angiographic studies before and after endovascular treatment. Neuroradiology 44:347-354, 2002

12. Kameda W, Kawanami T, Kurita K, Daimon M, Kayama T, Hosoya T, et al: Lateral and medial medullary infarction: a comparative analysis of 214 patients. Stroke 35:694-699, 2004

13. Kim JS: Pure lateral medullary infarction: clinical-radiological correlation of 130 acute, consecutive patients. Brain 126:1864-1872, 2003

14. Kim JS, Han YS: Medial medullary infarction: clinical, imaging, and outcome study in 86 consecutive patients. Stroke 40:3221-3225, 2009

15. Kim K, Lee HS, Jung YH, Kim YD, Nam HS, Nam CM, et al: Mechanism of medullary infarction based on arterial territory involvement. J Clin Neurol 8:116-122, 2012

16. Kühn AL, Kan P, Massari F, Lozano JD, Hou SY, Howk M, et al: Endovascular reconstruction of unruptured intradural vertebral artery dissecting aneurysms with the Pipeline embolization device. J Neurointerv Surg 8:1048-1051, 2016

17. Lee JM, Kim TS, Joo SP, Yoon W, Choi HY: Endovascular treatment of ruptured dissecting vertebral artery aneurysms-long-term follow-up results, benefits of early embolization, and predictors of outcome. Acta Neurochir (Wien) 152:1455-1465, 2010

18. Mahmood A, Dujovny M, Torche M, Dragovic L, Ausman JI: Microvascular anatomy of foramen caecum medullae oblongatae. J Neurosurg 75:299-304, 1991

19. Marinković S, Milisavljević M, Gibo H, Maliković A, Djulejić V: Microsurgical anatomy of the perforating branches of the vertebral artery. Surg Neurol 61:190-197, 2004

20. Mercier PH, Brassier G, Fournier HD, Picquet J, Papon X, Lasjaunias P: Vascular microanatomy of the pontomedullary junction, posterior inferior cerebellar arteries, and the lateral spinal arteries. Interv Neuroradiol 14:49-58, 2008
21. Mizutani T, Aruga T, Kirino T, Miki Y, Saito I, Tsuchida $\mathrm{T}$ : Recurrent subarachnoid hemorrhage from untreated ruptured vertebrobasilar dissecting aneurysms. Neurosurgery 36:905-913, 1995

22. Narata AP, Yilmaz H, Schaller K, Lovblad KO, Pereira VM: Flow-diverting stent for ruptured intracranial dissecting aneurysm of vertebral artery. Neurosurgery 70:982-989, 2012

23. Park SI, Kim BM, Kim DI, Shin YS, Suh SH, Chung EC, et al: Clinical and angiographic follow-up of stent-only therapy for acute intracranial vertebrobasilar dissecting aneurysms. AJNR Am J Neuroradiol 30:1351-1356, 2009

24. Peluso JP, van Rooij WJ, Sluzewski M, Beute GN, Majoie $\mathrm{CB}$ : Endovascular treatment of symptomatic intradural vertebral dissecting aneurysms. AJNR Am J Neuroradiol 29:102-106, 2008

25. Rabinov JD, Hellinger FR, Morris PP, Ogilvy CS, Putman CM: Endovascular management of vertebrobasilar dissecting aneurysms. AJNR Am J Neuroradiol 24:1421-1428, 2003

26. Sugiu K, Tokunaga K, Watanabe K, Sasahara W, Ono S, Tamiya T, et al: Emergent endovascular treatment of ruptured vertebral artery dissecting aneurysms. Neuroradiology 47:158-164, 2005

27. Suzuki S, Kurata A, Iwamoto K, Sato K, Niki J, Miyazaki T, et al: Endovascular surgery using stents for vertebral artery dissecting aneurysms and a review of the literature. Minim Invasive Neurosurg 51:193-198, 2008

28. Yamada M, Kitahara T, Kurata A, Fujii K, Miyasaka Y: Intracranial vertebral artery dissection with subarachnoid hemorrhage: clinical characteristics and outcomes in conservatively treated patients. J Neurosurg 101:25-30, 2004

29. Yamakawa H, Yoshimura S, Iwama T: Anterior spinal artery as a collateral channel in patients with acute bilateral vertebral artery occlusions. Two case reports. Neurol Med Chir (Tokyo) 49:354-358, 2009

30. Yamaura A, Watanabe Y, Saeki N: Dissecting aneurysms of the intracranial vertebral artery. J Neurosurg 72:183-188, 1990

\section{Disclosures}

The authors report no conflict of interest concerning the materials or methods used in this study or the findings specified in this paper.

\section{Author Contributions}

Conception and design: Aihara, Naito, Yoshimoto. Acquisition of data: Aihara, Naito, Yoshimoto. Analysis and interpretation of data: Aihara, Naito, Yoshimoto. Drafting the article: Aihara. Critically revising the article: Aihara. Reviewed submitted version of manuscript: Aihara, Shimizu, Matsumoto, Asakura, Miyamoto, Yoshimoto. Approved the final version of the manuscript on behalf of all authors: Aihara. Statistical analysis: Aihara. Administrative/technical/material support: Aihara. Study supervision: Aihara.

\section{Correspondence}

Masanori Aihara, Department of Neurosurgery, Gunma University Graduate School of Medicine, 3-39-22 Showa-machi, Maebashi, Gunma 371-8511, Japan. email: masa.a6221@gmail.com. 